\title{
Recent Advances in Bimetallic Transition Metal Nitrides for Hydrogen Evolution Reaction
}

\author{
Sang Heon Park, Duck Hyun Youn ${ }^{\dagger}$ \\ Department of Chemical Engineering, Kangwon National University, \\ Chuncheon, Gangwon-do 24341, Republic of Korea.

\section{수소 생산 반응을 위한 바이메탈릭 전이금속 질소화물의 최근 연구 동향} \\ 박상헌, 윤덕현 ${ }^{\dagger}$ \\ 강원대학교 화학공학과
}

(Received February 18 2021; Revised March 3 2021; Accepted March 3 2021)

\begin{abstract}
s
Electrochemical water splitting combined with renewable energy sources is widely considered as a promising route for clean and efficient hydrogen production. For wide-spread application of water splitting system, development of economical and efficient non-precious electrocatalyst is required to replace typical precious metal catalysts in hydrogen evolution reactions (HER). Although transition metal nitrides (TMNs) are promising HER catalysts owing to the high electrical conductivity and unique electronic structure, monometallic nitrides still showed inferior activity than precious metal catalysts. Recently, to improve the HER activity of monometallic TMNs, much attention is paid to bimetallic TMNs, which are expected to show a synergy between two distinct metals. This review highlights the recent progress on the development of bimetallic TMNs and their HER performances.
\end{abstract}

Keywords: Water splitting, Hydrogen evolution reaction, transition metal nitride, Bimetallic nitride

'Corresponding Author : Duck Hyun Youn

E-mail: youndh@kangwon.ac.kr 


\section{1. 서론}

화석연료의 사용으로 인한 자원 고갈 및 환경오염 문 제가 야기되면서 화석연료를 대체할 신재생 에너지 개 발의 필요성이 증대되고 있다. 여러 신재생 에너지원 중 수소는 풍부한 물로부터 제조될 수 있고, 에너지 밀도 가 높으며 (수소 $143 \mathrm{MJ} / \mathrm{kg}$, 천연가스 $54 \mathrm{MJ} / \mathrm{kg}$, 석탄 $24 \mathrm{MJ} / \mathrm{kg})$, 온실가스인 이산화탄소 배출 없이 높은 에 너지 변환 효율을 나타내기 때문에 지속 가능한 에너지 원으로 주목 받고 있다. 따라서 다가올 수소 경제에 대 비한 수소에너지의 생산, 저장 및 이용 관련 기술 개발 이 필수적이며, 특히 수소 생산 기술의 경쟁력 확보가 매우 중요한 시점이다. ${ }^{1-4)}$ 다양한 수소 생산 방법 중 태 양광과 (혹은 풍력) 연계한 형태의 수전해 시스템(물 전 기분해, Water splitting)은 물을 공급 원료로 사용하여 온실가스 및 오염물질을 배출하지 않고 수소를 생산하 는 청정한 수소 생산 시스템으로 장기적인 관점에서 연 구가 진행되고 있다. ${ }^{5-7)}$

물 전기분해가 일어나는 전해조는 수소 발생 반응 (Hydrogen Evolution Reaction, HER)과 산소 발생 반 응(Oxygen Evolution Reaction, OER)이 일어나는 수 소극(cathode)과 산소극(anode)으로 구성되어 있다. 물 전기분해를 위해 외부 전압이 양 전극에 인가되면 물 분 자는 수소와 산소로 분해되며, 이때 전체 반응식은 다음 과 같이 표현된다.

표준상태 T, P 조건 $(\mathrm{T}=298.15 \mathrm{~K}, \mathrm{P}=1 \mathrm{~atm})$ 에서 전기화학 반응이 일어나기 위해서는 $1.23 \mathrm{~V}$ 의 전압을 가해주어야 한다. 하지만 실제 작동 전압 $\left(\mathrm{E}_{\mathrm{op}}\right)$ 은 $1.23 \mathrm{~V}$ 에 초과 전압이 더해지는데 이를 과전압(overpotential, $\eta)$ 이라고 하며 다음과 같이 나타낼 수 있다.

$$
E_{\mathrm{op}}=1.23 V+\eta_{\mathrm{a}}+\eta_{\mathrm{c}}+\eta_{\text {other }}
$$

Table. 1. Reaction of water splitting in acid and alkaline media.

\begin{tabular}{c|c|c}
\hline & Acid & Alkaline \\
\hline Total reaction & \multicolumn{2}{|c|}{$\mathrm{H}_{2} \mathrm{O} \rightarrow \mathrm{H}_{2}+1 / 2 \mathrm{O}_{2}$} \\
\hline Cathode & $2 \mathrm{H}^{+}+2 \mathrm{e}^{-} \rightarrow \mathrm{H}_{2}$ & $2 \mathrm{H}_{2} \mathrm{O}^{+}+2 \mathrm{e}^{-} \rightarrow \mathrm{H}_{2}+2 \mathrm{OH}^{-}$ \\
\hline Anode & $\mathrm{H}_{2} \mathrm{O} \rightarrow 2 \mathrm{H}^{+}+1 / 2 \mathrm{O}_{2}+2 \mathrm{e}^{-}$ & $2 \mathrm{OH} \rightarrow \mathrm{H}_{2} \mathrm{O}+1 / 2 \mathrm{O}_{2}+2 \mathrm{e}^{-}$ \\
\hline
\end{tabular}

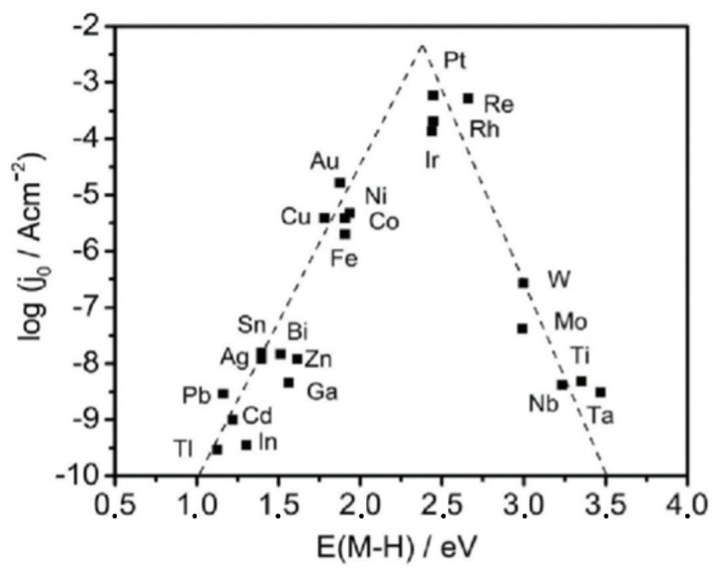

Fig. 1. Volcano plot for the hydrogen evolution reaction. ${ }^{9)}$ Reproduced from Zeradjanin et al. Electroanalysis 2016; 28: 2256-69, with permission of Wiley.'

과전압은 $\operatorname{anode}\left(\eta_{\mathrm{a}}\right)$ 와 cathode $\left(\eta_{\mathrm{c}}\right)$ 에 존재하는 고유 한 활성화 장벽뿐만 아니라 전해질이나 회로에서 발생 하는 저항 $\left(\eta_{\text {other }}\right)$ 을 극복하기 위해 필요하다. 따라서 물 전기 분해 효율을 높이기 위해서 과전압을 줄이는 것이 중요하며, 특히 $\eta_{\mathrm{a}}$ 와 $\eta_{\mathrm{c}}$ 는 촉매를 사용하여 줄일 수 있기 때문에 활성이 좋은 촉매일수록 과전압을 크게 줄일 수 있다. ${ }^{5)}$

수소 발생 반응에서 촉매의 활성을 나타내는 중요한 지표는 수소 결합 에너지(Hydrogen Binding Energy, $\mathrm{HBE})$ 이다. 이를 잘 나타내는 그래프가 $\mathrm{HBE}$ 와 교환전 류밀도로 도시한 volcano plot이다. (Fig. 1) Sabatier 원칙에 근거하여 너무 강하거나 너무 약한 $\mathrm{HBE}$ 는 전체 반응에 유리하지 않다. 너무 강한 $\mathrm{HBE}$ 는 생성물(수소) 의 탈착이 어렵고, 너무 약한 $\mathrm{HBE}$ 는 전하전달이 잘 일 어나지 않는다. ${ }^{89}$ ) 따라서 적당한 $\mathrm{HBE}$ 를 가지며 높은 전류 밀도를 나타내는 백금 $(\mathrm{Pt})$ 은 volcano plot의 꼭지 점 부근에 위치하여 활성이 가장 좋은 수소 발생 촉매로 알려져 있다. 하지만 귀금속인 백금은 한정된 매장량으 로 인한 비싼 가격 문제가 있기 때문에 실제 상용화에는 한계가 존재한다. 따라서 백금을 대체하기 위한 저가의 비귀금속 기반 신규 촉매 개발이 필수적이다.

전이금속 질소화물(Transition Metal Nitrides, $\mathrm{TMNs}$ )은 전이금속 격자 내에 질소 원자가 도입되어 생 


\section{특 집 ㅁㅃ 박상헌, 윤덕현}

긴 화합물로써 원래의 금속과는 전혀 다른 특성을 지니 며 특히 융점, 경도, 내마모성, 초전도성, 그리고 부식 저항성과 같은 우수한 물리적 특성을 지녀 절삭 공구 및 내화물용 코팅제로 사용되었다. ${ }^{10,11)}$ 또한, 귀금속과 유 사한 전자구조를 나타내어 수첨공정 및 수첨탈황공정과 같은 화학 공정 분야에서 귀금속 촉매의 대체 촉매로 연 구가 진행되었다. ${ }^{12-14)}$ 최근에는 $\mathrm{HER}, \mathrm{OER}$ 반응뿐 아 니라, ${ }^{15)}$ 산소 환원 반응(Oxygen Reduction Reaction, ORR), 메탄올 산화 반응(Methanol Oxidation Reaction, MOR) 등의 전기화학 반응에서 전이금속 질 소화물 촉매가 폭넒게 연구되고 있다. ${ }^{16-19)}$ 특히 HER 분야에서는 $\mathrm{MoN},{ }^{20)} \mathrm{Mo}_{2} \mathrm{~N},{ }^{21)} \mathrm{Ni}_{3} \mathrm{~N},{ }^{22)} \mathrm{CoN},{ }^{23)} \mathrm{TiN},{ }^{24)}$ $\mathrm{TaN}^{25)} \mathrm{Ta}_{3} \mathrm{~N}_{5}{ }^{26}$ 과 같은 물질들이 촉매 활성을 나타내는 것으로 보고되고 있다.

이러한 전이금속 질소화물 기반 촉매의 활성을 증가 시키기 위해 나노구조화 또는 탄소 소재와의 복합화 형 태의 질소화물이 보고되고 있으나, 기존의 탄소화물 (carbide), 인화물(phosphide), 황화물(sulfide) 기반 촉 매보다 수소 생산 활성이 낮은 실정이다. 이러한 한계 를 극복하기 위해 최근 두 종류의 전이금속으로 구성된 바이메탈릭 전이금속 질소화물 (Bimetallic Transition Metal Nitride)이 주목을 받고 있다. 바이메탈릭 촉매 는 두 전이금속 사이의 시너지 효과로 인해 단일 금속 (Monometallic) 촉매 보다 향상된 HER 촉매 활성을 가 지는 것으로 알려져 있다. ${ }^{27-29)}$ 바이메탈릭 촉매에서 두 금속의 존재는 더 풍부한 활성점과 향상된 전자 전도도 를 제공할 수 있어 전기화학 반응에 유리하다. 또한, 바 이메탈릭 촉매는 금속 양이온의 원소 조성 비율을 조절 하여 전자 구조를 조절할 수 있기 때문에 촉매의 물리 . 화학적 특성을 향상시킬 수 있는 잠재력을 지닌다. ${ }^{29,30)}$ 따라서 본 논문에서는 $\mathrm{HER}$ 촉매로써 사용된 바이메탈 릭 전이금속 질소화물 연구 사례를 소개하고자 한다.

\section{2. 본론}

\subsection{Nickel Molybdenum Nitride}

$\mathrm{Ni}$ 과 $\mathrm{Mo}$ 의 도입으로 형성한 $\mathrm{Ni}-\mathrm{Mo}-\mathrm{N}$ 물질은 높은
HER 활성을 나타내는 대표적인 바이메탈릭 전이금속 질소화물이다. 효율적인 물 분해 능력을 갖춘 $\mathrm{Ni}$ 과 강한 수소 결합에너지를 나타내는 $\mathrm{Mo}$ 의 시너지 효과는 $\mathrm{HER}$ 활성 향상에 기여할 수 있기 때문에 많은 연구가 진행되 고 있다. ${ }^{28,31)} \mathrm{Ni}-\mathrm{Mo}-\mathrm{N}$ 촉매의 HER 활성은 Sasaki 그 룹에 의해 최초로 제시되었다. ${ }^{32)} \mathrm{Ni}, \mathrm{Mo}$ 전구체를 $\mathrm{H}_{2}$ 와 $\mathrm{NH}_{3}$ 로 환원 및 질화 시켜 $\mathrm{Mo}_{2} \mathrm{~N}$ 과 $\mathrm{Ni}_{2} \mathrm{Mo}_{3} \mathrm{~N}$ 이 혼재한 나노 시트 형태의 $\mathrm{NiMoN}_{\mathrm{x}}$ 를 탄소 지지체에 $\left(\mathrm{NiMoN}_{\mathrm{x}} /\right.$ C) 제조하였다. (Fig. 2a) $\mathrm{NiMoN}_{\mathrm{x}}$ 나노 시트는 얇고 평 평한 스택 구조를 보이며, 최대 $2 \mathrm{~nm}$ 의 간격의 단일 시 트 형태로 존재하였다. (Fig. $2 \mathrm{~b}-\mathrm{d}$ ) $0.1 \mathrm{M} \mathrm{HClO}_{4}$ 전 해질 조건에서 $\mathrm{NiMoN}_{\mathrm{x}} / \mathrm{C}$ 촉매는 $78 \mathrm{mV}$ 의 낮은 개시 전압과 $35.9 \mathrm{mV} / \mathrm{dec}$ 의 낮은 타펠 기울기를 나타내어 monometallic nitride $\left(\mathrm{MoN} / \mathrm{C}, \mathrm{Mo}_{2} \mathrm{~N} / \mathrm{C}\right)$ 촉매보다 월 등히 뛰어난 HER 활성과 안정성을 나타내었다. (Fig. $2 \mathrm{e}-\mathrm{h}) \mathrm{Ni}$ 의 도입으로 낮아진 $\mathrm{Mo}$ 의 d-band center가 수소 흡착 에너지를 낮추어 흡착된 수소의 재결합을 원 활하게 하였고, 결과적으로 $\mathrm{NiMON}_{\mathrm{x}}$ 촉매의 $\mathrm{HER}$ 활성 이 증가한 것으로 제시되었다.

최근 $\mathrm{Ni}_{0.2} \mathrm{Mo}_{0.8} \mathrm{~N}$ 형태의 $\mathrm{Ni}-\mathrm{Mo}-\mathrm{N}$ 촉매들이 $\mathrm{HER}$ 에 활발히 적용되고 있다. 대부분의 $\mathrm{Ni}_{0.2} \mathrm{Mo}_{0.8} \mathrm{~N}$ 촉매는 수열합성을 통해 바이메탈릭 산화물을 합성하고 이어서 $\mathrm{NH}_{3}$ 를 이용한 질화 과정을 통해 $\mathrm{Ni}_{0.2} \mathrm{Mo}_{0.8} \mathrm{~N}$ 를 합성하 는 2 단계 열처리 방식으로 제조되었다. Chen 그룹은 $\mathrm{Ni}$ foam substrate 위에 Ni-Mo-N nanowires(NiMoN/ $\mathrm{NF}$ )가 성장한 형태의 $\mathrm{HER}$ 촉매를 개발하였다. ${ }^{33)} \mathrm{Ni}$, $\mathrm{Mo}$ 전구체와 $\mathrm{Ni}$ foam을 수열합성하여 $\mathrm{Ni}$ foam 위에 $\mathrm{NiMoO}_{4}$ 를 성장시키고 $\left(\mathrm{NiMoO}_{4} / \mathrm{NF}\right), \mathrm{NH}_{3}$ 분위기에 서 $300 \sim 600{ }^{\circ} \mathrm{C}$ 에서 열처리하여 $\mathrm{Ni}_{3} \mathrm{~N}$ 과 $\mathrm{Ni}_{0.2} \mathrm{Mo}_{0.8} \mathrm{~N}$ 가 혼재된 촉매를 제조하였다. 제조된 $\mathrm{NiMoN} / \mathrm{NF}$ 촉매 는 지름 50 100 nm의 나노 와이어 형태를 보이며, 열 처리 온도가 상승할수록 $\mathrm{Ni}_{0.2} \mathrm{Mo}_{0.8} \mathrm{~N}$ phase가 증가하 는 것으로 나타났다. Substrate로 사용된 Ni foam은 높은 전기 전도도와 다공성 계층 구조를 지니기 때문에 전자 흐름 경로를 제공하고 촉매 활성점과 전해질의 상 호작용을 향상시킬 수 있다. ${ }^{34,35)} 450{ }^{\circ} \mathrm{C}$ 에서 열처리한 $\mathrm{NiMoN} / \mathrm{NF}-450$ 촉매가 $1 \mathrm{M} \mathrm{KOH}$ 전해질 조건에서 
a)
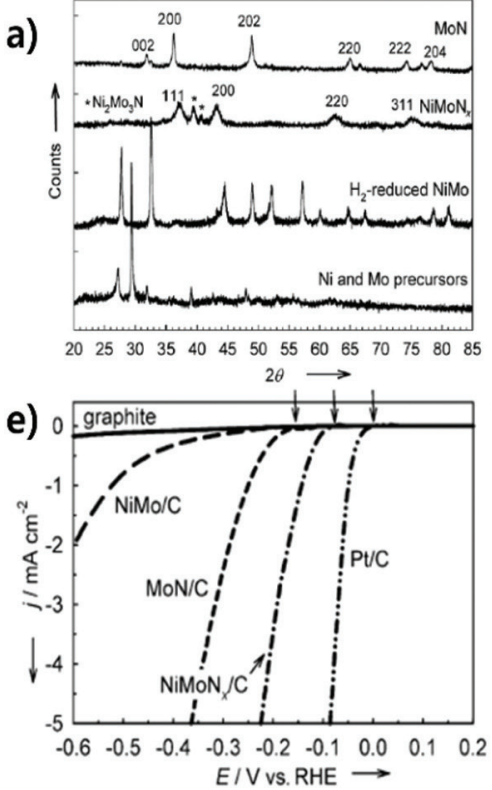

b)
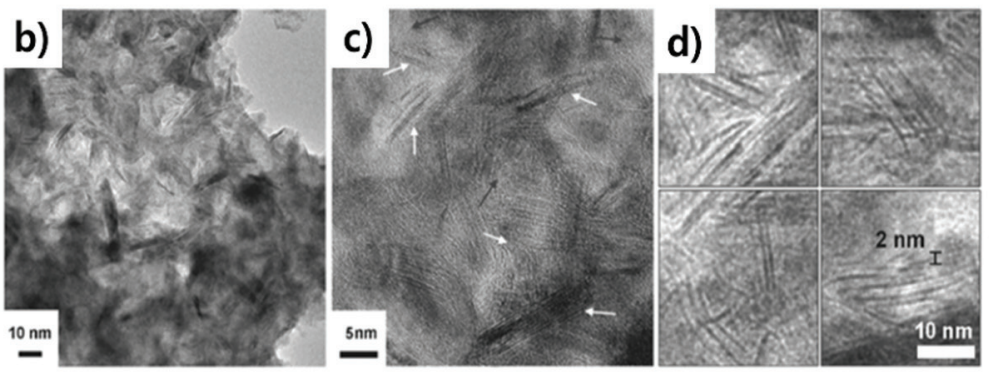

f)
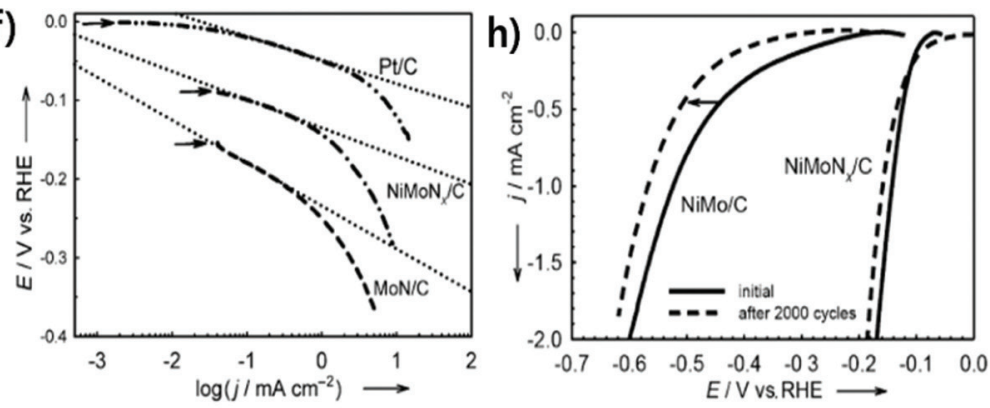

Fig. 2. a) XRD patterns and b-d) TEM images of $\mathrm{NiMoN}_{x} / \mathrm{C}$ catalysts. e) The polarization curves $\left(0.1 \mathrm{M} \mathrm{HClO}_{4}\right)$, f) Tafel plots, and h) Stability tests for NiMoN ${ }_{x} / C$ catalysts. ${ }^{32)}$ Reproduced from Chen et al. Angew. Chem. Int. Ed. 2012; 51: 6131-5, with permission of Wiley. ${ }^{32)}$

가장 높은 $\mathrm{HER}$ 활성을 나타내었다. 전류 밀도 $10 \mathrm{~mA} /$ $\mathrm{cm}^{2}$ 에 도달하는 데 필요한 과전압 $\left(\eta_{10}\right) 22 \mathrm{mV}$ 를 기록하 며 $\mathrm{Pt} / \mathrm{C}$ 에 근접한 매우 우수한 $\mathrm{HER}$ 활성을 기록하였으 며 20 시간 작동에서 높은 내구성을 보였다. Ni foam 위에 $\mathrm{Ni}_{0.2} \mathrm{Mo}_{0.8} \mathrm{~N}$ 를 직접 성장시켰기 때문에 binder가 필요 없으며, 전해질과 더 많은 활성점이 반응하는 것이 높은 활성의 원인으로 제시되었다.

제 3 의 전이금속을 도펀트로 사용하여 $\mathrm{Ni}-\mathrm{Mo}-\mathrm{N}$ 촉 매의 활성을 극대화한 연구사례도 보고되고 있다. ${ }^{36-39)}$ Chen 그룹은 core-shell 구조의 $\mathrm{MoO}_{3} @ \mathrm{Ni}(\mathrm{OH})_{2}$ 나노 튜브(nanotube, NT)에 $\mathrm{Fe}$ 를 첨가하여 상온에서 교반 후 $\mathrm{NH}_{3}$ 분위기에서 열처리하여 다공성 계층 구조의 3 차 원 $\mathrm{Ni}-\mathrm{Fe}-\mathrm{MoN}$ NTs촉매를 합성하였다. ${ }^{36)} \mathrm{Fe}$ 가 도핑 되면서 격자 간 거리의 증가를 유도하여 $\mathrm{Ni}-\mathrm{Fe}-\mathrm{MoN}$ 의 $\mathrm{Ni}_{0.2} \mathrm{Mo}_{0.8} \mathrm{~N}$ peak 위치가 낮은 회절 각으로 이동하 였다. 따라서 제조된 $\mathrm{Ni}-\mathrm{Fe}-\mathrm{MoN}$ 촉매는 $\mathrm{Fe}$-doped $\mathrm{Ni}_{0.2} \mathrm{Mo}_{0.8} \mathrm{~N}$ 와 $\mathrm{Ni}_{3} \mathrm{Fe}$ 결정 구조로 구성되어 있음을 알 수 있다. (Fig. 3a) Ni-Fe-MoN NTs의 지름은 약 300 $\mathrm{nm}$, 나노 튜브의 두께는 약 $80 \mathrm{~nm}$ 로 관찰되었으며 외 부 벽은 많은 나노 시트 구조로 형성된 다공성 구조를 보인다. (Fig. 3b) $1 \mathrm{M} \mathrm{KOH}$ 전해질 조건에서 $\mathrm{Ni}-\mathrm{Fe}-$ $\mathrm{MoN} N \mathrm{NT}$ 촉매는 $55 \mathrm{mV}$ 의 $\eta_{10}$ 값을 기록하며 $\mathrm{Ni}-\mathrm{MoN}$ $\mathrm{NTs}$ 촉매보다 뛰어난 HER 활성 및 안정성을 나타내 었다. (Fig. $3 \mathrm{c}$ ) Fe의 도입이 $\mathrm{Ni}$ 원자의 전자 구조 변형 을 이끌어 내어 전하 전달 저항을 감소시켰으며 또한, $\mathrm{Ni}-\mathrm{Fe}-\mathrm{MoN} \mathrm{NTs}$ 의 다공성 관형 특징은 안쪽과 바깥 쪽 표면을 포함한 넓은 표면적을 제공하여 활성점과 전 해질 접촉을 증가시켰다. 따라서 $\mathrm{Ni}-\mathrm{Fe}-\mathrm{MoN} \mathrm{NTs}$ 의 뛰어난 $\mathrm{HER}$ 활성은 $\mathrm{Fe}$ 도입과 3 차원 다공성 관형 구 조에서 기인한 것으로 나타났다. 이와 비슷한 방법으 로 $\mathrm{MoO}_{3}$ nanowire(NR)에 $\mathrm{Co}$ 를 도입하여 수열합성법 과 $\mathrm{NH}_{3}$ 를 이용한 질화 과정을 통해 $\mathrm{Co}$ 가 도핑된 다공성 $\mathrm{NiMoN} \mathrm{NRS}_{\mathrm{S}}(\mathrm{Co}-\mathrm{NiMoN} \mathrm{NRs})$ 가 제조되었다. ${ }^{37)}$ 이전 연구와 마찬가지로 $\mathrm{NiMoN} N R s$ 촉매는 $\mathrm{Ni}_{0.2} \mathrm{Mo}_{0.8} \mathrm{~N}$ 과 $\mathrm{Ni}_{3} \mathrm{~N}$ 으로 구성되었으나 Co 도입 후에는 $\mathrm{Ni}_{3} \mathrm{~N}$ 가 사라지 고 $\mathrm{Ni}_{0.2} \mathrm{Mo}_{0.8} \mathrm{~N}$ 과 $\mathrm{Ni} / \mathrm{Co}$ 혹은 CoNi alloy phase가 나 

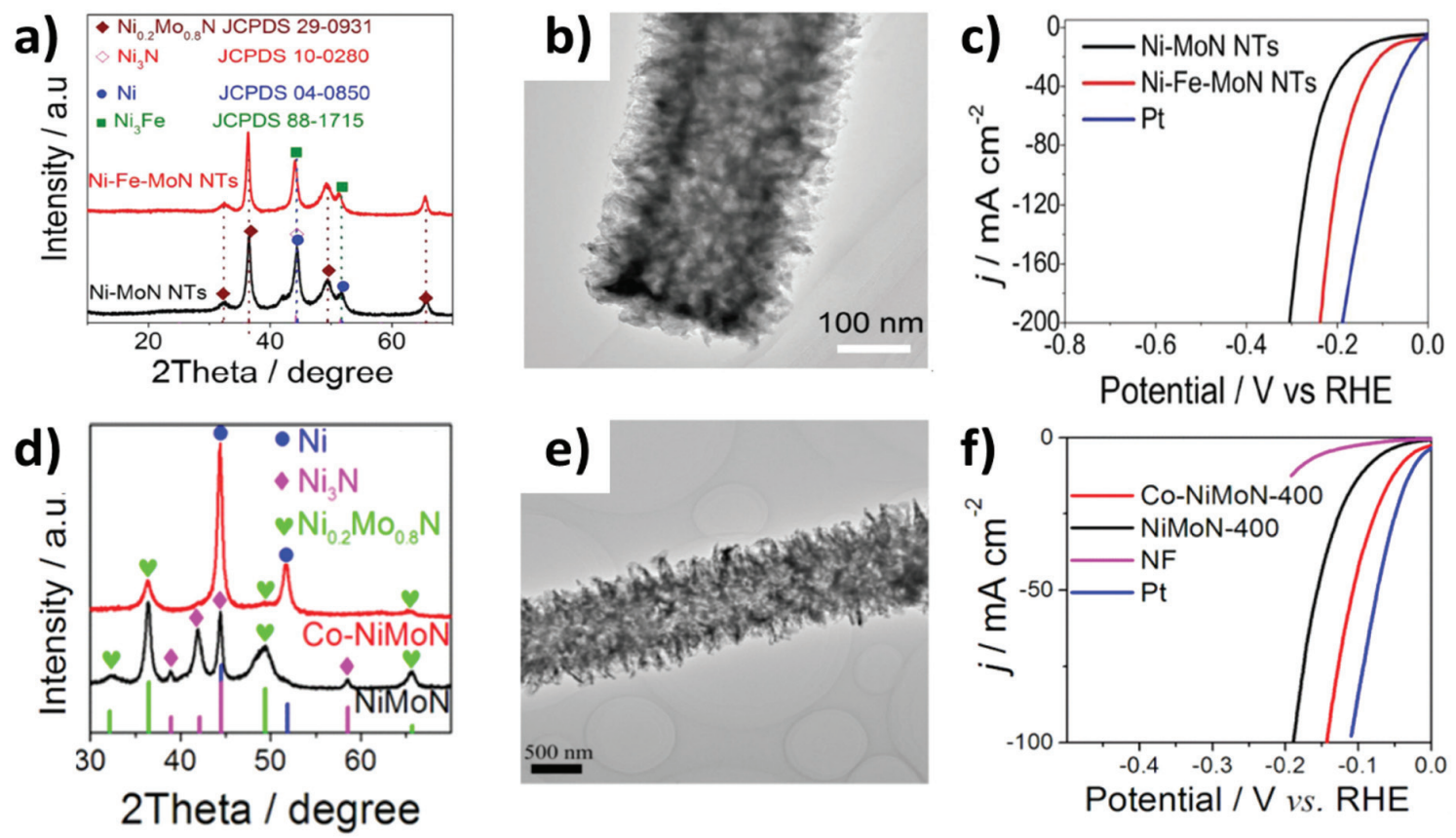

Potential / V vs. RHE

Fig. 3. a) XRD patterns, b) TEM images and c) The polarization curves (1 $\mathrm{M} \mathrm{KOH}$ ) for Ni-Fe-MoN NTs HER catalyst. ${ }^{36)}$ Reproduced from Zhu et al. Adv. Energy Mater. 2018; 8: 1802327, with permission of Wiley. ${ }^{36)}$ c) XRD patterns, e) TEM images and f) The polarization curves $(1 \mathrm{M} \mathrm{KOH})$ for Co-NiMoN NRs HER catalyst. ${ }^{37)}$ Reproduced from Yin et al. ACS Appl. Mater. Interfaces 2019; 11: 27751-9, with permission of American Chemical Society. ${ }^{37)}$

타난 것을 알 수 있다. (Fig. $3 \mathrm{~d}-\mathrm{e}$ ) $1 \mathrm{M} \mathrm{KOH}$ 전해질에 서 NiMoN NRs은 $90 \mathrm{mV}$ 의 $\eta_{10}$ 값을 기록한 반면, $\mathrm{Co}-$ $\mathrm{NiMoN} \mathrm{NRs}$ 은 $\eta_{10} 45 \mathrm{mV}$ 을 나타내어 Co 도핑이 HER 활성 향상에 기여한 것을 알 수 있다. $\mathrm{Co}-\mathrm{NiMoN} N R s$ 의 격자 왜곡 및 비정질/결정질 계면과 같은 많은 결함 이 촉매의 활성점을 많이 생성한 것으로 제시되었다. (Fig. 3f)

Huang 그룹은 vanadium을 도입하여 $\mathrm{Ni}_{0.2} \mathrm{Mo}_{0.8} \mathrm{~N}$ 의 $\mathrm{HER}$ 활성을 극대화한 $\mathrm{V}-\mathrm{Ni}_{0.2} \mathrm{Mo}_{0.8} \mathrm{~N}$ 을 개발하였 다. ${ }^{38)} \mathrm{Ni}$ foam과 $\mathrm{Ni}, \mathrm{Mo}, \mathrm{V}$ 전구체를 수열 합성하 여 $\mathrm{V}-\mathrm{NiMoO}_{4} / \mathrm{NF}$ 전구체를 제조하고, $\mathrm{NH}_{3}$ 를 이용 한 질화 과정을 거쳐 $\mathrm{V}-\mathrm{Ni}_{0.2} \mathrm{Mo}_{0.8} \mathrm{~N}$ 촉매를 합성하였 다. 이렇게 생성된 $\mathrm{V}-\mathrm{Ni}_{0.2} \mathrm{Mo}_{0.8} \mathrm{~N}$ 는 $\mathrm{Ni}$ foam에 해당 하는 $\mathrm{Ni}$ 금속과 단일상 $\mathrm{Ni}_{0.2} \mathrm{Mo}_{0.8} \mathrm{~N}$ 으로 구성되어 있 으며, $\mathrm{V}$ 도핑으로 격자 간격이 감소하여 XRD peak가 pure $\mathrm{Ni}_{0.2} \mathrm{Mo}_{0.8} \mathrm{~N}$ 보다 높은 회절 각으로 위치하였다. 또 한, $\mathrm{V}-\mathrm{Ni}_{0.2} \mathrm{Mo}_{0.8} \mathrm{~N}$ 의 $80 \sim 100 \mathrm{~nm}$ 지름의 nanowire
는 수많은 작은 나노 입자들로 구성되어있다. $1 \mathrm{M} \mathrm{KOH}$ 전해질에서 $\mathrm{V}-\mathrm{Ni}_{0.2} \mathrm{Mo}_{0.8} \mathrm{~N}$ 촉매는 $\mathrm{Ni}_{0.2} \mathrm{Mo}_{0.8} \mathrm{~N}$ 촉매보 다 약 $40 \mathrm{mV}$ 낮은 $39 \mathrm{mV}$ 의 $\eta_{10}$ 값을 기록하였고, 200 $\mathrm{mA} / \mathrm{cm}^{2}$ 의 고전류밀도에서 $178 \mathrm{mV}$ 의 과전압을 기 록하며 우수한 HER 활성을 나타내었다. 밀도범함수 이론 기반 계산에서 $\mathrm{V}-\mathrm{Ni}_{0.2} \mathrm{Mo}_{0.8} \mathrm{~N}(0.56 \mathrm{eV})$ 은 pure $\mathrm{Ni}_{0.2} \mathrm{Mo}_{0.8} \mathrm{~N}(0.86 \mathrm{eV})$ 에 비해 더 낮은 물 분해 에너지 장벽을 나타냈다. $\mathrm{V}$ 도핑은 $\mathrm{Ni}_{0.2} \mathrm{Mo}_{0.8} \mathrm{~N}$ 표면에 흡착된 물 분자를 분해하여 $\mathrm{H}^{*}$ (촉매 표면에 흡착된 수소 원자) 의 형성을 촉진하기 때문에 Volmer $\operatorname{step}\left(\mathrm{H}_{2} \mathrm{O}+\mathrm{e}^{-} \rightarrow\right.$ $\left.\mathrm{H}^{*}+\mathrm{OH}^{-}\right)$을 더욱 원활히 일어나게 한다. HER 활성을 나타내는 중요한 지표인 수소 흡착 에너지 $\left(\Delta G_{H^{*}}\right)$ 는 열 중성 조건 $\left(\Delta G_{H^{*}}=0\right)$ 에 근접할수록 이상적인 수소 흡 . 탈착 능력을 나타낸다. ${ }^{40)} \mathrm{V}-\mathrm{Ni}_{0.2} \mathrm{Mo}_{0.8} \mathrm{~N}(-0.27 \mathrm{eV})$ 의 $\Delta G_{H^{*}}$ 는 $\mathrm{Ni}_{0.2} \mathrm{Mo}_{0.8} \mathrm{~N}(-0.71 \mathrm{eV})$ 보다 열 중성 조건에 가 깝기 때문에 $\mathrm{V}$ 도핑이 수소 흡 · 탈착을 원활하게 하여 $\mathrm{HER}$ 활성을 강화하는 요인이라고 설명하였다. 
a)

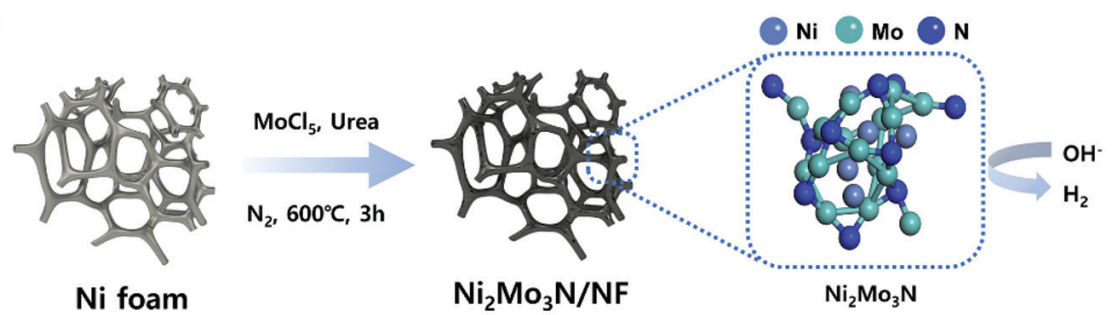

b)
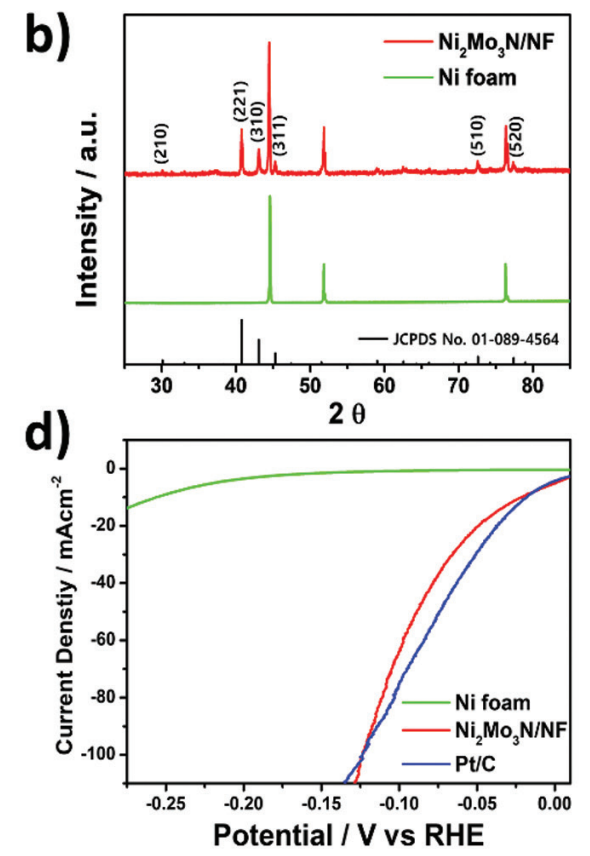

c)

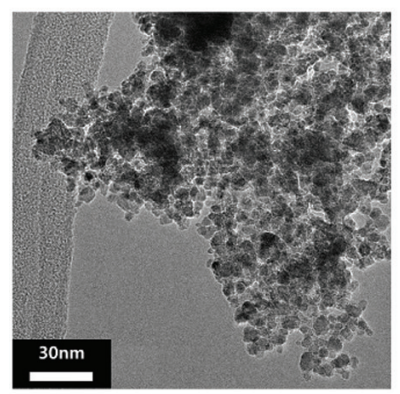

e)

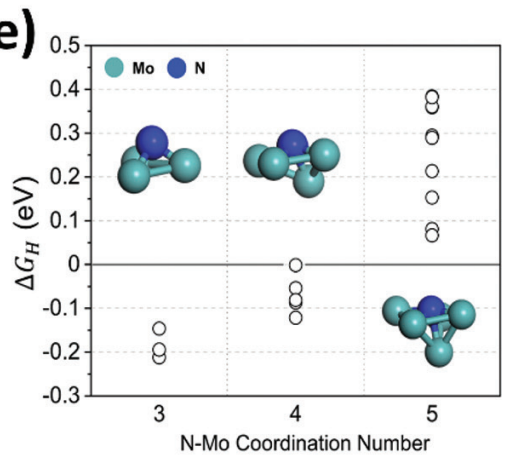

Fig. 4. a) Schematic illustration of the synthetic method for $\mathrm{Ni}_{2} \mathrm{Mo}_{3} \mathrm{~N} / \mathrm{NF}$. b) XRD patterns, c) TEM image and d) The polarization curves $(1 \mathrm{M} \mathrm{KOH})$ for $\mathrm{Ni}_{2} \mathrm{Mo}_{3} \mathrm{~N} / \mathrm{NF}$. e) DFT results for overall $\mathrm{H}$-adsorption strength trend with respect to coordination number(CN) of N-Mo bonding. ${ }^{41)}$ Reproduced from Park et al. J. Mater. Chem. A 2021; 9: 4945-51, with permission of Royal Society of Chemistry.

기존의 $\mathrm{Ni}_{0.2} \mathrm{Mo}_{0.8} \mathrm{~N}$ 와 다른 구조를 지니는 $\mathrm{Ni}_{2} \mathrm{Mo}_{3} \mathrm{~N}$ 촉매 역시 높은 $\mathrm{HER}$ 활성을 보이는 $\mathrm{Ni}-\mathrm{Mo}-\mathrm{N}$ 의 하나 로 최근 보고되었다. Huang 그룹은 $\mathrm{Ni}_{0.2} \mathrm{Mo}_{0.8} \mathrm{~N}$ 합성 법에서 $\mathrm{NH}_{3}$ 가스 대신 $\mathrm{Ar} / \mathrm{N}_{2} / \mathrm{H}_{2}$ 혼합 가스를 사용하 여 $\mathrm{V}-\mathrm{Ni}_{2} \mathrm{Mo}_{3} \mathrm{~N}$ 촉매를 합성하였다. ${ }^{39)} \mathrm{Ni}_{2} \mathrm{Mo}_{3} \mathrm{~N}$ 촉매 $\left(\eta_{10}=101 \mathrm{mV}, \eta_{100}=230 \mathrm{mV}\right)$ 는 $\mathrm{Ni}_{0.2} \mathrm{Mo}_{0.8} \mathrm{~N}$ 촉매 $(\eta$ ${ }_{10}=108 \mathrm{mV}, \eta_{100}=250 \mathrm{mV}$ )보다 뛰어난 HER 활성을 나타내었으며, $\mathrm{V}$ 도핑 후에 $\mathrm{V}-\mathrm{Ni}_{2} \mathrm{Mo}_{3} \mathrm{~N}$ 의 $\mathrm{HER}$ 활성 $(\eta$ $\left.{ }_{10}=54 \mathrm{mV}, \eta_{100}=117 \mathrm{mV}\right)$ 은 더욱 증가하였다. 또한, $\mathrm{V}-\mathrm{Ni}_{2} \mathrm{Mo}_{3} \mathrm{~N}$ 촉매의 Mo site $(-0.93 \mathrm{eV}), \mathrm{N}$ site $(-0.15$ $\mathrm{eV})$ 는 $\mathrm{Ni}_{2} \mathrm{Mo}_{3} \mathrm{~N}$ 촉매의 $\mathrm{Mo} \operatorname{site}(-1.02 \mathrm{eV}), \mathrm{N}$ site $(-$
$0.19 \mathrm{eV}$ )보다 열 중성 조건에 가까운 $\Delta G_{H^{*}}$ 값을 나타내 어 $\mathrm{V}$ 도핑이 $\mathrm{HER}$ 활성을 강화하는 요인인 것을 밝혔 다. Youn 연구진에서는 기존 $\mathrm{Ni}-\mathrm{Mo}-\mathrm{N}$ 촉매 합성법 의 2 단계 열처리와 유독성 가스 $\left(\mathrm{NH}_{3}\right)$ 사용이라는 단점 을 극복한 간단하고 경제적인 $\mathrm{Ni}-\mathrm{Mo}-\mathrm{N}$ 합성법을 개발 하였다. ${ }^{41)} \mathrm{Mo}$-urea 용액을 $\mathrm{Ni}$ foam과 함께 질소 흐름 하에서 동시에 열처리하여 $\mathrm{Ni}_{2} \mathrm{Mo}_{3} \mathrm{~N} / \mathrm{NF}$ 촉매를 합성하 였다. (Fig. 4a) Urea를 질소원으로 사용하여 $\mathrm{NH}_{3}$ 사 용을 피했고, 열처리 과정 중 $\mathrm{Ni}$ foam이 $\mathrm{Ni}$ 원료로 사 용되어 추가 $\mathrm{Ni}$ 첨가가 필요하지 않아 안전하고 경제적 이라는 장점이 있다. 제조된 $\mathrm{Ni}_{2} \mathrm{Mo}_{3} \mathrm{~N} / \mathrm{NF}$ 는 $\mathrm{Ni}$ foam 
a)

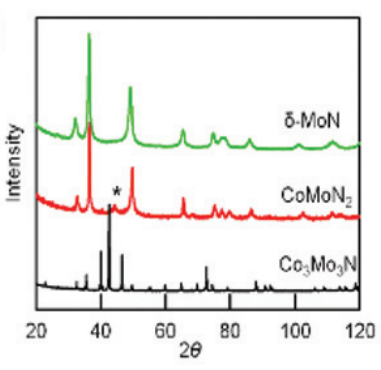

c)

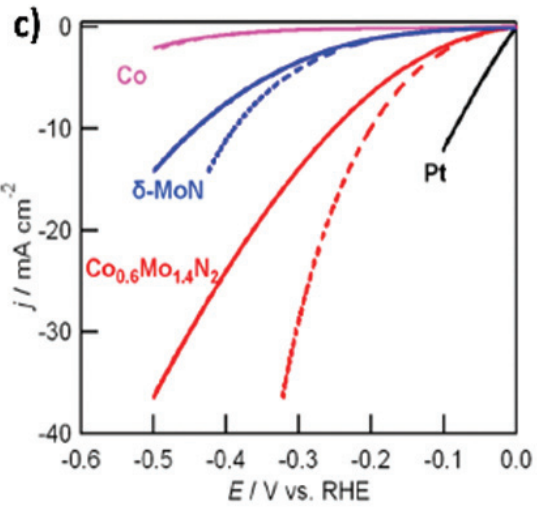

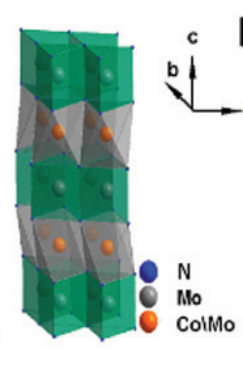

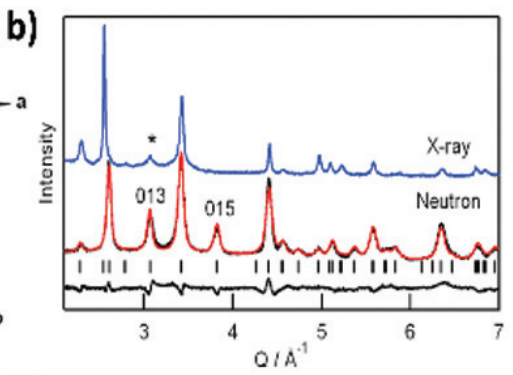

d)

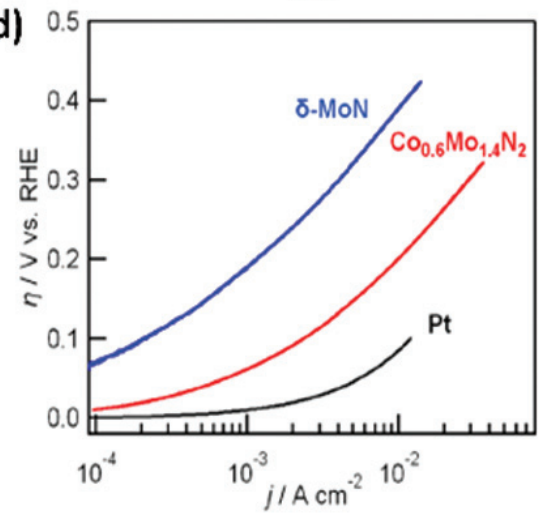

Fig. 5. a) XRD patterns and 4-layerd crystal structure of $\mathrm{CoMoN}_{2}$. b) Rietveld refinements of neutron diffraction for $\mathrm{CoMoN}$. $\mathrm{C}-\mathrm{d}$ ) The polarization curves and Tafel plots $\left(0.1 \mathrm{M} \mathrm{HClO}_{4}\right)$ for $\left.\mathrm{Co}_{0.6} \mathrm{Mo}_{1.4} \mathrm{~N}_{2}{ }^{42}{ }^{2}\right)$ Reproduced from Cao et al. J. Am. Chem. Soc. 2015; 137: 9927-36, with permission of American Chemical Society. ${ }^{42}$

위에 단일상 $\mathrm{Ni}_{2} \mathrm{Mo}_{3} \mathrm{~N}$ 이 성장하였으며, 평균 입자 크 기 약 $7 \mathrm{~nm}$ 의 나노 입자로 구성되어 있다. (Fig. $4 \mathrm{~b}-$ c) $1 \mathrm{M} \mathrm{KOH}$ 전해질 조건에서 $\mathrm{Ni}_{2} \mathrm{Mo}_{3} \mathrm{~N} / \mathrm{NF}$ 촉매는 10 , $50,100 \mathrm{~mA} / \mathrm{cm}^{2}$ 에 도달하는데 $21.3,89,123.8 \mathrm{mV}$ 의 과전압을 나타내어 매우 우수한 HER 활성을 보유하였 다. (Fig. $4 \mathrm{~d}$ ) 본 연구진은 $\mathrm{Ni}_{2} \mathrm{Mo}_{3} \mathrm{~N} / \mathrm{NF}$ 촉매의 $\mathrm{HER}$ 활성점을 규명하기 위해 실시한 밀도범함수이론 계산 을 통해 $\mathrm{N}$ 활성점의 구조적 특성이 $\mathrm{HER}$ 활성에 큰 영 향을 미치는 것을 확인하였다. 특히 특정 $\mathrm{N} \operatorname{site}(\mathrm{N}-\mathrm{Mo}$ coordination number $=4$ )에서 열 중성 조건에 가장 가까운 $\Delta G_{H^{*}}$ 값(평균 $-0.07 \mathrm{eV}$ )을 나타내는 것을 확인 하였다. (Fig. 4e)

\subsection{Cobalt Molybdenum Nitride}

Khalifah 그룹은 상대적으로 낮은 $\mathrm{MoN}$ 의 고유 $\mathrm{HER}$ 활성을 개선하기 위해 $\mathrm{Co}$ 를 도핑 하여 mixed closepacked cobalt molybdenum nitride 촉매를 개발하
였다. ${ }^{42)} \mathrm{CoMoO}_{4}$ 전구체를 $\mathrm{NH}_{3}$ 흐름 하에서 열처리하 여 $\mathrm{CO}_{0.6} \mathrm{Mo}_{1.4} \mathrm{~N}_{2}$ 촉매를 합성하였다. Neutron powder diffraction을 통해 $\mathrm{Co}(\mathbb{I})$ 와 $\mathrm{Mo}(\mathbb{I I})$ 가 차지하는 octahedral sites와 $\mathrm{Mo}(\mathbb{I} \sim \mathbb{V})$ 가 위치하는 trigonalprismatic sites가 교대로 층이 있는 4-layered mixed closed packed 구조임을 확인하였다. (Fig. 5a-b) 0.1 $\mathrm{M} \mathrm{HClO}_{4}$ 전해질 조건에서 $\mathrm{Co}_{0.6} \mathrm{Mo}_{1.4} \mathrm{~N}_{2}$ 촉매는 $10 \mathrm{~mA} /$ $\mathrm{cm}^{2}$ 전류밀도에 도달하는데 $200 \mathrm{mV}$ 의 과전압을 기록 하며 $\mathrm{MoN}$ 촉매보다 향상된 $\mathrm{HER}$ 활성을 나타내었다. (Fig. $5 \mathrm{c}-\mathrm{d}$ )

\subsection{Nickel Iron Nitride}

$\mathrm{Ni}-\mathrm{Fe}$ alloy는 고활성의 물 전기분해 촉매로 많은 연 구가 진행된 물질 중 하나이며, 이의 질화 형태인 $\mathrm{Ni}-$ $\mathrm{Fe}-\mathrm{N}$ 촉매도 최근 많은 연구가 진행되고 있다. ${ }^{29,43,44)}$ Zhang 그룹은 reverse microemulsion method를 사 용하여 제조한 초박형 $\mathrm{NiFe}-\mathrm{LDH}$ (Layered Double 
a)

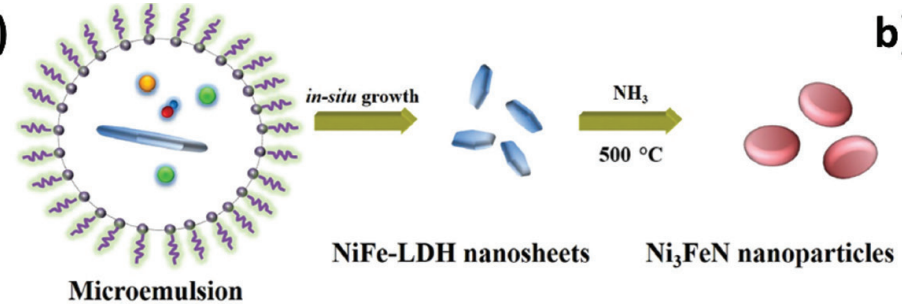

c)

on oleylamine $\mathrm{O} \mathrm{Fe}^{3+}$ - $\mathrm{Ni}^{2+} \oplus \mathrm{OH}^{-}$

Macroscopic view
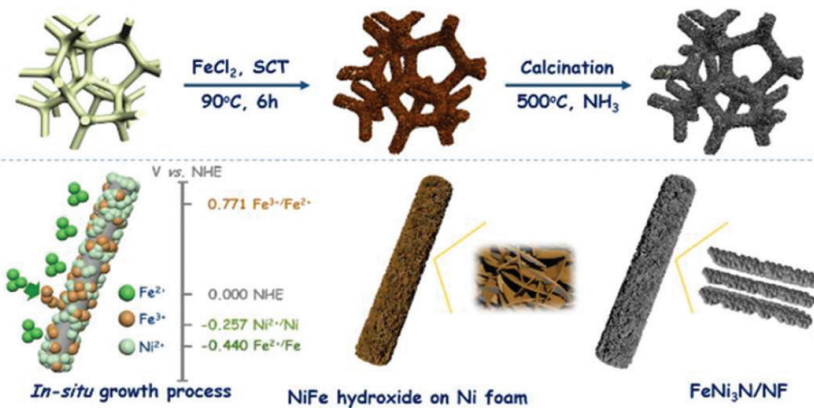

Microcosmic view
Microxide on b)

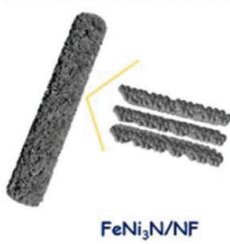

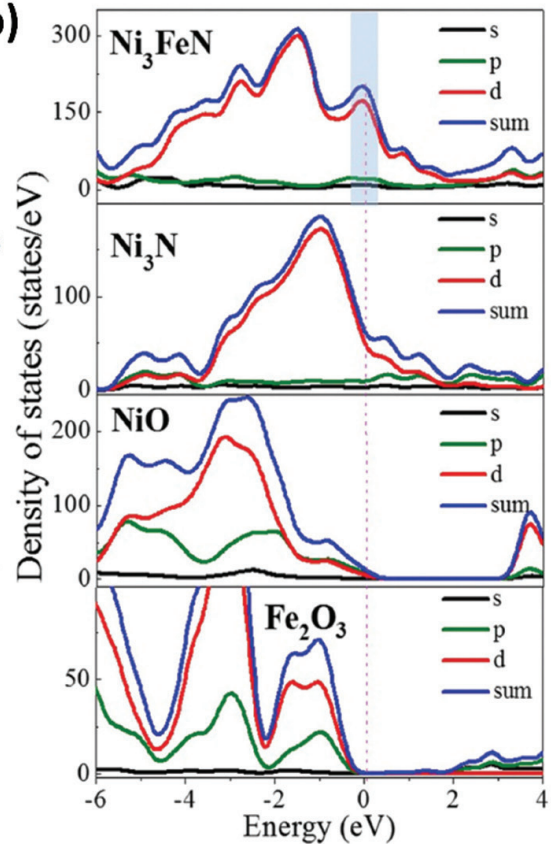

Fig. 6. a) Schematic illustration of the formation of $\mathrm{Ni}_{3} \mathrm{FeN}$ nanoparticles. b) Total and partial electronic density of state calculated for $\mathrm{Ni}_{3} \mathrm{FeN}, \mathrm{Ni}_{3} \mathrm{~N}, \mathrm{NiO}$, and $\mathrm{Fe}_{2} \mathrm{O}_{3}{ }^{45)}$ Reproduced from Waterhouse et al. Adv. Energy. Mater. 2016; 6: 1502585, with permission of Wiley. ${ }^{45)}$ c) Schematic illustration of the formation of FeNi $\mathrm{N}_{\mathrm{NFF}}{ }^{47)}$ Reproduced from Zhang et al. Chem. Mater. 2016; 28: 6934-41, with permission of American Chemical Society. ${ }^{47}$

Hydroxide) 나노 시트 전구체를 $\mathrm{NH}_{3}$ 를 이용한 질화 과 정을 통해 $\mathrm{Ni}_{3} \mathrm{FeN}-\mathrm{NPs}$ 를 합성하였다. (Fig. 6a) ${ }^{45}$ 이 렇게 제조된 $\mathrm{Ni}_{3} \mathrm{FeN}-\mathrm{NPs}$ 는 약 $100 \mathrm{~nm}$ 의 입자 크기 와 약 $9 \mathrm{~nm}$ 두께를 나타내었다. $1 \mathrm{M} \mathrm{KOH}$ 전해질 조 건에서 $\mathrm{Ni}_{3} \mathrm{FeN}-\mathrm{NPs}$ 촉매는 $10,100 \mathrm{~mA} / \mathrm{cm}^{2}$ 에서 과 전압 $158,416 \mathrm{mV}$ 를 기록하였으며, 특히 과전압 343 $\mathrm{mV}$ 이상 전압 범위에서 $\mathrm{Pt} / \mathrm{C}$ 보다 높은 전류 밀도를 나 타내 우수한 HER 활성을 나타냈다. Fermi level 근처 의 $\mathrm{Ni}_{3} \mathrm{FeN}$ 의 밴드 구조 및 density of state(DOS)가 뚜렷한 간격 없이 연속적이므로 $\mathrm{Ni}_{3} \mathrm{FeN}$ 이 금속 특성 을 보유하여 뛰어난 전기 전도도와 전자 전달 능력을 갖 춘 것으로 제시되었다. (Fig. 6b) 이와 비슷한 시도로, $\mathrm{Ni}_{3} \mathrm{Fe} \mathrm{LDH}$ 전구체를 질화하여 제조한 nanoparticlesstacked porous $\mathrm{Ni}_{3} \mathrm{FeN}$ (NSP- $\mathrm{Ni}_{3} \mathrm{FeN}$ ) 촉매가 Wang 그룹에 의해 보고되었다. ${ }^{46)} \mathrm{LDH}$ 전구체의 층상 구조를 유지한 $\mathrm{Ni}_{3} \mathrm{FeN}$ 나노 시트는 $20 \sim 30 \mathrm{~nm}$ 크기의 나노 입자들로 구성되어 있기 때문에 활성점의 노출을 증가
시켜 향상된 $\mathrm{HER}$ 활성을 보였다.

$\mathrm{Ni}$ foam, carbon cloth와 같은 전도성 기판에 촉매 를 직접 성장시킨 $\mathrm{Ni}-\mathrm{Fe}-\mathrm{N}$ 촉매는 기존 분말 촉매에 비해 전기 전도도가 높고 우수한 기계적 특성을 보인 다. ${ }^{47.48)} \mathrm{XiaO}$ 그룹은 간단한 화학 침전 반응을 통해 $\mathrm{Ni}$ foam 위에 $\mathrm{NiFe}(\mathrm{OH})_{\mathrm{x}}$ 나노 시트를 성장시킨 뒤, 질화 열처리하여 $\mathrm{FeNi}_{3} \mathrm{~N} / \mathrm{NF}$ 촉매를 합성하였다. (Fig. 6c) ${ }^{47)}$ 합성 과정에서 전극 기판으로 사용된 $\mathrm{Ni}$ foam은 $\mathrm{Fe}$ 전 구체 $\left(\mathrm{Fe}^{3+}\right)$ 의 redox etching에 의해서 느리게 방출되 는 $\mathrm{Ni}$ 전구체 역할을 하였기 때문에, 추가적인 산화제 나 $\mathrm{Ni}$ 전구체가 필요 없는 장점이 있다. 가열 용액에서 $\mathrm{Fe}^{2+}$ 는 $\mathrm{Ni}$ 과 반응하지 않고 산소와 물과 반응하여 $\mathrm{Fe}^{3+}$ 로 산화되고 (반응식 1), $\mathrm{Ni}$ foam은 생성된 $\mathrm{Fe}^{3+}$ 에 의 해 redox-etched 되어 $\mathrm{Ni}$ 이온을 서서히 방출시킨다. (반응식 2) 이때, $\mathrm{Ni}^{2+}$ 와 $\mathrm{Fe}^{3+}$ 가 $\mathrm{Ni}$ foam위에 침전되어 $\mathrm{NiFe}$ 수산화물을 형성한다고 보고하였다. (반응식 3) 


\section{특 집 ㅁㅃ 박상헌, 윤덕현}

a)
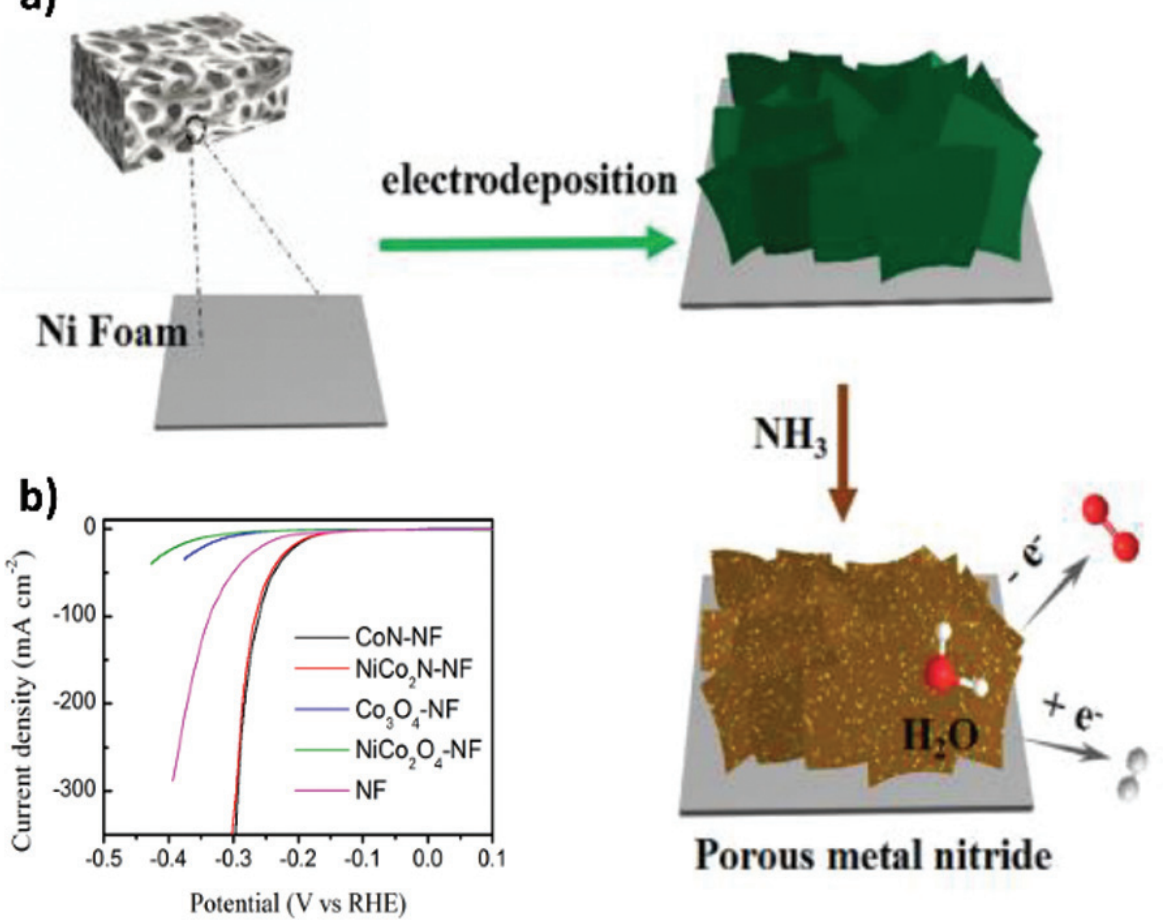

Porous metal nitride

Fig. 7. a) Schematic illustration of the formation of $\mathrm{NiCO}_{2} \mathrm{~N}-\mathrm{NF}$. b) The polarization curves $(1 \mathrm{M} \mathrm{KOH})$ for $\mathrm{NiCO}_{2} \mathrm{~N}-\mathrm{NF}$. ${ }^{49)}$ Reproduced from Wang et al. ChemsusChem 2017; 10: 4170-7, with permission of Wiley. ${ }^{49}$

1. $4 \mathrm{Fe}^{2+}+\mathrm{O}_{2}+2 \mathrm{H}_{2} \mathrm{O} \leftrightarrow 4 \mathrm{Fe}^{3+}+4 \mathrm{OH}^{-}$

2. $2 \mathrm{Fe}^{3+}+\mathrm{Ni} \rightarrow 2 \mathrm{Fe}^{2+}+\mathrm{Ni}^{2+}$

3. $\mathrm{XNi}^{2+}+\mathrm{Fe}^{3+}+(2 \mathrm{x}+3) \mathrm{OH}^{-} \rightarrow \mathrm{Ni}_{\mathrm{x}} \mathrm{FeOH} \mathrm{H}_{2 \mathrm{x}+3}$

$\mathrm{FeNi}_{3} \mathrm{~N} / \mathrm{NF}$ 촉매는 낮은 과전압 $\left(\eta_{10}=75 \mathrm{mV}\right)$ 과 타 펠 기울기 $(98 \mathrm{mV} / \mathrm{dec})$ 를 나타내었으며, 특히 400 시간 이상 안정성을 유지하여 뛰어난 $\mathrm{HER}$ 활성을 보유한 것 으로 나타났다.

\subsection{Nickel Cobalt Nitride}

Zhang 그룹은 전기 증착법을 통해서 $\mathrm{Ni}$ foam 위에 성장한 $\mathrm{Ni}-\mathrm{Co}$ 수산화물 전구체를 제조하고, 이를 $\mathrm{NH}_{3}$ 열처리하여 다공성 nickel cobalt nitride $\left(\mathrm{NiCO}_{2} \mathrm{~N}\right)$ 나 노 시트를 합성하였다. ${ }^{49)} 3$-전극 시스템에서 수행된 전 기 증착 공정은 각각 $\mathrm{Ni}$ foam, $\mathrm{Ag} / \mathrm{AgCl}, \mathrm{Pt}$ plate를 작업 전극, 기준 전극, 상대 전극으로 사용하였다. 전 해질은 $\mathrm{Ni}^{2+} / \mathrm{Co}^{2+}$ 몰 비율 $1: 2$ 로 녹아 있는 $50 \mathrm{~mL}(0.1$
$\mathrm{M})$ 용액을 사용하여 $-0.1 \mathrm{~V}$ 에서 10 분간 전기 증착을 실 시하였다. (Fig. $7 \mathrm{a}$ ) 다공성 구조의 $\mathrm{NiCO}_{2} \mathrm{~N}$ 나노 시트 는 Ni foam 위에 수직으로 성장하였으며, 이러한 다공 성 나노 시트가 서로 연결되어 거품과 같은 연속 구조체 를 형성하여 기계적 안정성을 향상시켰다. $1 \mathrm{M} \mathrm{KOH}$ 전 해질에서 실시한 전기화학 실험에서 $\mathrm{NiCO}_{2} \mathrm{~N}-\mathrm{NF}$ 촉매 는 다른 촉매에 비해 뛰어난 $\mathrm{HER}$ 활성 $\left(\eta_{10}=180 \mathrm{mV}\right)$ 을 나타내었다. (Fig. 7b)

금속-유기 구조체(Metal-Organic Framework, $\mathrm{MOF}$ )의 직접 열처리는 균일한 전이금속 기반 복합재 를 제조하기 위한 효과적인 방식으로 알려져 있다. ${ }^{50-}$ 53) $\mathrm{MOF}-74-\mathrm{M}(\mathrm{M}=\mathrm{Co}, \mathrm{Ni}, \mathrm{Mg}, \mathrm{Zn}$ 등 $)$ 는 $\mathrm{MOF}$ 결 정 구조에 영향을 끼치지 않고 다른 금속과 결합하여 균 일한 바이메탈릭 질소화물 복합체 제조가 가능하다는 이점이 있다. ${ }^{54)} \mathrm{Guo}$ 그룹은 $\mathrm{MOF}-74$ 를 질화하여 넓 은 $\mathrm{pH}$ 범위에서 $\mathrm{HER}$ 활성이 뛰어난 다공성 막대 모양 cobalt-nickel nitride $\left(\mathrm{Co}_{\mathrm{x}} \mathrm{Ni}_{\mathrm{y}} \mathrm{N}\right)$ 를 보고하였다. (Fig. 


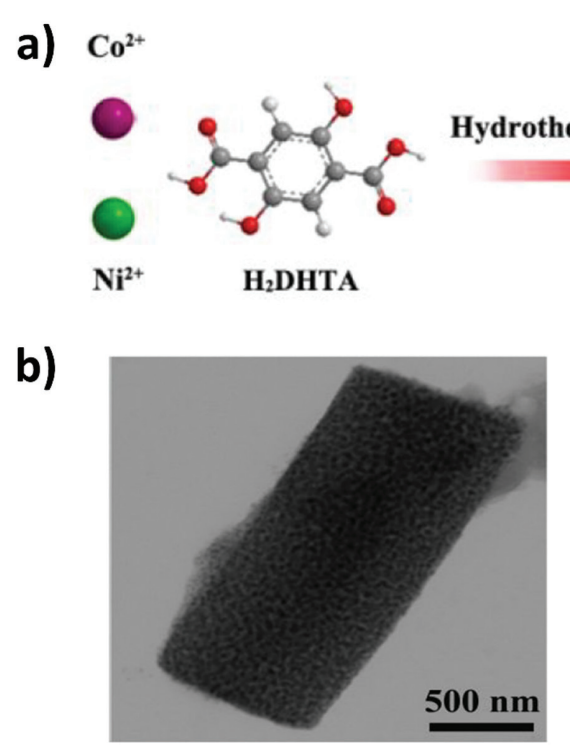

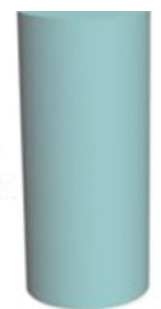

1) Air $400^{\circ} \mathrm{C}$

2) $\mathrm{NH}_{3} 500{ }^{\circ} \mathrm{C}$

MOF-74

Coxiy N

c)

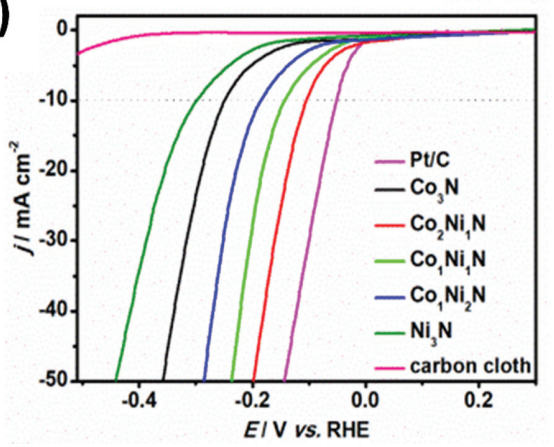

Fig. 8. a) Schematic illustration of the formation of $\mathrm{Co}_{x} \mathrm{Ni}_{y} \mathrm{~N}$. b) TEM images and c) The polarization curves (1 M KOH) for $\mathrm{Co}_{x} \mathrm{Ni}_{y} \mathrm{~N}^{55)}$ Reproduced from Feng et al. ACS Appl. Mater. Interfaces 2019; 11: 8018-24, with permission of American Chemical Society. ${ }^{55)}$

8a) ${ }^{55)}$ Fig. $8 b$ 에서 볼 수 있듯이 $\mathrm{Co}_{\mathrm{x}} \mathrm{Ni}_{\mathrm{y}} \mathrm{N}$ 은 약 $760 \mathrm{~nm}$ 의 지름을 갖는 일차원 막대 구조 형태를 보유하였다. $1 \mathrm{M} \mathrm{KOH}$ 전해질에서 실시한 전기화학 실험에서, 제조 한 $\mathrm{Co}_{\mathrm{x}} \mathrm{Ni}_{\mathrm{y}} \mathrm{N}$ 촉매 사이 중 $\mathrm{Co}_{2} \mathrm{Ni}_{1} \mathrm{~N}$ 촉매는 약 $21 \mathrm{mV}$ 의 개시 전압 $\left(\eta_{\text {onset }}\right)$ 을 나타내어 $\mathrm{Co}_{1} \mathrm{Ni}_{1} \mathrm{~N}\left(\eta_{\text {onset }}=42 \mathrm{mV}\right)$, $\mathrm{Co}_{1} \mathrm{Ni}_{2} \mathrm{~N}\left(\eta_{\text {onset }}=88 \mathrm{mV}\right)$ 에 비해 나타내 가장 낮은 과전 압을 기록하였다. 또한, $\mathrm{Co}_{2} \mathrm{Ni}_{1} \mathrm{~N}$ 촉매는 $102.6 \mathrm{mV}$ 의 $\eta$ 10 값과 24 시간 안정성을 보유하여 뛰어난 $\mathrm{HER}$ 활성을 나타내었다. (Fig. 8c) $0.5 \mathrm{M} \mathrm{H}_{2} \mathrm{SO}_{4}, 1.0 \mathrm{M} \mathrm{PBS}$ 에서 실시한 전기화학 실험에서도 $\mathrm{Co}_{2} \mathrm{Ni}_{1} \mathrm{~N}$ 촉매의 $\eta_{10}$ 은 각 각 $92,152.8 \mathrm{mV}$ 를 기록하며 염기, 산, 중성 전해질 조 건에서 모두 뛰어난 $\mathrm{HER}$ 활성을 나타내었다. $\mathrm{Co}_{\mathrm{x}} \mathrm{Ni}_{\mathrm{y}} \mathrm{N}$ 촉매의 우수한 $\mathrm{HER}$ 활성은 $\mathrm{MOF}$ 전구체 적용으로 인 한 조성 및 구조 제어와 균일한 원소 분포 그리고 계층 적 다공성 구조에 의한 높은 비표면적, 풍부한 메조 기 공 및 고분산된 촉매 활성점 때문인 것으로 제시되었다.

\section{3. 결론}

온실가스 및 오염물질을 배출하지 않는 청정한 수소 생산법인 수전해 시스템의 상용화를 위해서는 고효율의 비귀금속 기반 촉매의 개발이 필수적이다. 전이금속 질 소화물은 우수한 물리화학적 특성으로 수전해 시스템의 $\mathrm{HER}$ 촉매로 연구가 진행되고 있으며 그 활성을 향상시 키기 위해 최근 바이메탈릭 질소화물 촉매가 폭넓게 연 구되고 있다. $\mathrm{Ni}-\mathrm{Mo}-\mathrm{N}, \mathrm{Co}-\mathrm{Mo}-\mathrm{N}, \mathrm{Ni}-\mathrm{Fe}-\mathrm{N}, \mathrm{Ni}-$ $\mathrm{Co}-\mathrm{N}$ 과 같은 바이메탈릭 질소화물은 두 전이금속의 시 너지 효과로 인한 활성점 증대 및 전자 전도도 향상으로 모노메탈릭 질소화물에 비해 월등히 뛰어난 HER 활성 을 기록하였으며, Ni foam, carbon cloth와 같은 전도 성 기판에 성장시킬 경우 활성 및 안정성의 추가적인 향 상을 달성하였다.

최근 나노 기술과 계산화학 등의 발전은 특정 물성을 제어할 수 있는 금속 조합의 예측과 그에 따른 바이메탈 릭 질소화물의 제조를 가능케 하고 있다. 이러한 바이메 
탈릭 질소화물은 앞서 언급한 $\mathrm{HER}$ 반응뿐 아니라 OER 및 산소환원반응 (Oxygen Reduction Reaction, ORR) 등 다양한 분야에 적용되어 그 중요성이 높아지고 있다. 바이메탈릭 질소화물의 실제 응용까지는 추가적인 연구 가 필요하지만 효과적인 합성법 개발, 조성 및 구조 제 어 등 지속적인 발전이 이루어진다면 다양한 분야에서 신규 촉매 개발의 기회가 될 수 있을 것이다.

\section{REFERENCES}

1. I. Dincer, C. Acar, "Review and evaluation of hydrogen production methods for better sustainability." Int. J. Hydrog. Energy, 40 [34] 11094-111 (2015).

2. H.-C. Im, "전력저장을 위한 수소 에너지 이용 및 향후 전망(in Korean)” J. Electrical World, [465] 35-41(2015).

3. A. Ursua, L.M. Gandia, P. Sanchis, "Hydrogen Production From Water Electrolysis: Current Status and Future Trends." Proc. IEEE, 100 [2] 410-26 (2012)

4. J.A. Turner, "Sustainable hydrogen production." Science, 305 [5686] 972-4 (2004).

5. X. Zou, Y. Zhang, "Noble metal-free hydrogen evolution catalysts for water splitting." Chem. Soc. Rev., 44 [15] 5148-80 (2015).

6. G.H. Lee, M.H. Lee, Y. Kim, H.-K. Lim, D.H. Youn, "Facile synthesis of nanostructured molybdenum carbide/nitrogen-doped CNT-RGO composite via a modified urea glass route for efficient hydrogen evolution." J. Alloys Compd., 805 [15] 113-9 (2019).

7. H.M. Jo, Y. Kim, D.H. Youn, "One-pot synthesis of molybdenum carbide/N-doped carbon nanotube composite using nitrilotriacetic acid for efficient hydrogen evolution." J. Alloys Compd., 855 [25] 157420 (2021).

8. P. Quaino, F. Juarez, E. Santos, W. Schmickler, "Volcano plots in hydrogen electrocatalysis - uses and abuses." Beilstein J. Nanotechnol., 5 [1] 846-54 (2014).

9. A.R. Zeradjanin, J.P. Grote, G. Polymeros, K.J. Mayrhofer, "A Critical Review on Hydrogen Evolution Electrocatalysis: Re-exploring the Volcanorelationship." Electroanalysis, 28 [10] 2256-69 (2016).

10. D. Ham, J. Lee, "Transition Metal Carbides and Nitrides as Electrode Materials for Low Temperature Fuel Cells." Energies, 2 [4] 873-99 (2009).
11. D.H. Youn, G. Bae, S. Han, J.Y. Kim, J.-W. Jang, H. Park, S.H. Choi, J.S. Lee, "A highly efficient transition metal nitride-based electrocatalyst for oxygen reduction reaction: TiN on a CNT-graphene hybrid support." J. Mater. Chem. A, 1 [27] 8007-15 (2013).

12. E. Furimsky, "Metal carbides and nitrides as potential catalysts for hydroprocessing." Appl. Catal. A, 240 [1] 1-28 (2003).

13. R.C.V. McGee, S.K. Bej, L.T. Thompson, "Basic properties of molybdenum and tungsten nitride catalysts." Appl. Catal. A, 284 [1] 139-46 (2005).

14. J.G. Chen, "Carbide and Nitride Overlayers on Early Transition Metal Surfaces: Preparation, Characterization, and Reactivities." Chem. Rev., 96 [4] 1477-98 (1996).

15. X. Peng, C. Pi, X. Zhang, S. Li, K. Huo, P.K. Chu, "Recent progress of transition metal nitrides for efficient electrocatalytic water splitting." Sustain. Energ. Fuels, 3 [2] 366-81 (2019).

16. W.F. Chen, J.T. Muckerman, E. Fujita, "Recent developments in transition metal carbides and nitrides as hydrogen evolution electrocatalysts." Chem. Commun. (Camb), 49 [79] 8896-909 (2013).

17. S. Jin, "Are metal chalcogenides, nitrides, and phosphides oxygen evolution catalysts or bifunctional catalysts?.” ACS Energy Lett., 2 [8] 1937-8 (2017).

18. Y. Dong, Y. Deng, J. Zeng, H. Song, S. Liao, “A highperformance composite ORR catalyst based on the synergy between binary transition metal nitride and nitrogen-doped reduced graphene oxide." J. Mater. Chem. A, 5 [12] 5829-37 (2017).

19. O.M. Musthafa, S. Sampath, "High performance platinized titanium nitride catalyst for methanol oxidation." Chem. Commun., [1] 67-9 (2008).

20. J. Xie, S. Li, X. Zhang, J. Zhang, R. Wang, H. Zhang, B. Pan, Y. Xie, "Atomically-thin molybdenum nitride nanosheets with exposed active surface sites for efficient hydrogen evolution." Chem. Sci., 5 [12] 4615-20 (2014).

21. Z. Lv, M. Tahir, X. Lang, G. Yuan, L. Pan, X. Zhang, J.-J. Zou, "Well-dispersed molybdenum nitrides on a nitrogen-doped carbon matrix for highly efficient hydrogen evolution in alkaline media." J. Mater. Chem. A, 5 [39] 20932-7 (2017).

22. Z. Xing, Q. Li, D. Wang, X. Yang, X. Sun, “Self- 
supported nickel nitride as an efficient highperformance three-dimensional cathode for the alkaline hydrogen evolution reaction." Electrochim. Acta, 191 841-5 (2016).

23. Z. Xue, J. Kang, D. Guo, C. Zhu, C. Li, X. Zhang, Y. Chen, "Self-supported cobalt nitride porous nanowire arrays as bifunctional electrocatalyst for overall water splitting." Electrochim. Acta, 273 229-38 (2018).

24. P. Zheng, J. Zhao, J. Zheng, G. Ma, Z. Zhu, "Nonequilibrium partial oxidation of TiN surface for efficient visible-light-driven hydrogen production." $J$. Mater. Chem., 22 [24] 12116-20 (2012).

25. N.S. Alhajri, H. Yoshida, D.H. Anjum, A.T. GarciaEsparza, J. Kubota, K. Domen, K. Takanabe, "Synthesis of tantalum carbide and nitride nanoparticles using a reactive mesoporous template for electrochemical hydrogen evolution." J. Mater. Chem. A, 1 [40] 12606-16 (2013).

26. S. Wirth, F. Harnisch, M. Weinmann, U. Schröder, "Comparative study of IVB-VIB transition metal compound electrocatalysts for the hydrogen evolution reaction." Appl. Catal. B, 126 [25] 225-30 (2012).

27. M. Sankar, N. Dimitratos, P.J. Miedziak, P.P. Wells, C.J. Kiely, G.J. Hutchings, "Designing bimetallic catalysts for a green and sustainable future." Chem. Soc. Rev., 41 [24] 8099-139 (2012).

28. J. Jia, M. Zhai, J. Lv, B. Zhao, H. Du, J. Zhu, "Nickel Molybdenum Nitride Nanorods Grown on Ni Foam as Efficient and Stable Bifunctional Electrocatalysts for Overall Water Splitting." ACS Appl. Mater. Interfaces, 10 [36] 30400-8 (2018).

29. L. Trotochaud, S.L. Young, J.K. Ranney, S.W. Boettcher, "Nickel-iron oxyhydroxide oxygenevolution electrocatalysts: the role of intentional and incidental iron incorporation.” J. Am. Chem. Soc., 136 [18] 6744-53 (2014).

30. H. Liang, A.N. Gandi, D.H. Anjum, X. Wang, U. Schwingenschlögl, H.N. Alshareef, "Plasmaassisted synthesis of $\mathrm{NiCoP}$ for efficient overall water splitting." Nano lett., 16 [12] 7718-25 (2016).

31. J. Zhang, T. Wang, P. Liu, Z. Liao, S. Liu, X. Zhuang, M. Chen, E. Zschech, X. Feng, "Efficient hydrogen production on $\mathrm{MoNi}_{4}$ electrocatalysts with fast water dissociation kinetics." Nat. Commun., 8 [1] 15437 (2017).

32. W.F. Chen, K. Sasaki, C. Ma, A.I. Frenkel, N.
Marinkovic, J.T. Muckerman, Y. Zhu, R.R. Adzic, "Hydrogen-evolution catalysts based on non-noble metal nickel-molybdenum nitride nanosheets." Angew. Chem. Int. Ed. Engl., 51 [25] 6131-5 (2012).

33. Y. Wang, Y. Sun, F. Yan, C. Zhu, P. Gao, X. Zhang, Y. Chen, "Self-supported NiMo-based nanowire arrays as bifunctional electrocatalysts for full water splitting." J. Mater. Chem. A, 6 [18] 8479-87 (2018).

34. N.K. Chaudhari, H. Jin, B. Kim, K. Lee, "Nanostructured materials on 3D nickel foam as electrocatalysts for water splitting." Nanoscale, 9 [34] 12231-47 (2017).

35. M. Grden, M. Alsabet, G. Jerkiewicz, "Surface science and electrochemical analysis of nickel foams." ACS Appl. Mater. Interfaces, 4 [6] 3012-21 (2012).

36. C. Zhu, Z. Yin, W. Lai, Y. Sun, L. Liu, X. Zhang, Y. Chen, S.-L. Chou, "Fe-Ni-Mo Nitride Porous Nanotubes for Full Water Splitting and Zn-Air Batteries." Adv. Energy Mater., 8 [36] 1802327 (2018).

37. Z. Yin, Y. Sun, Y. Jiang, F. Yan, C. Zhu, Y. Chen, "Hierarchical Cobalt-Doped MolybdenumNickel Nitride Nanowires as Multifunctional Electrocatalysts.” ACS Appl. Mater. Interfaces, 11 [31] 27751-9 (2019).

38. P. Zhou, X. Lv, D. Xing, F. Ma, Y. Liu, Z. Wang, P. Wang, Z. Zheng, Y. Dai, B. Huang, "High-efficient electrocatalytic overall water splitting over vanadium doped hexagonal $\mathrm{Ni}_{0.2} \mathrm{Mo}_{0.8} \mathrm{~N}$." Appl. Catal. B, 263 118330 (2020).

39. P. Zhou, X. Lv, Y. Gao, Z. Liang, Y. Liu, Z. Wang, P. Wang, Z. Zheng, Y. Dai, B. Huang, "Synthesis of novel cubic $\mathrm{Ni}_{2} \mathrm{Mo}_{3} \mathrm{~N}$ and its electronic structure regulation by vanadium doping towards highefficient HER electrocatalyst." Electrochim. Acta, 337 [20]135689 (2020).

40. J.K. Nørskov, T. Bligaard, A. Logadottir, J. Kitchin, J.G. Chen, S. Pandelov, U. Stimming, "Trends in the exchange current for hydrogen evolution." $J$. Electrochem. Soc., 152 [3] J23-6 (2005).

41. S.H. Park, T.H. Jo, M.H. Lee, K. Kawashima, C.B. Mullins, H.-K. Lim, D.H. Youn, "Highly active and stable nickel-molybdenum nitride $\left(\mathrm{Ni}_{2} \mathrm{Mo}_{3} \mathrm{~N}\right)$ electrocatalyst for hydrogen evolution." J. Mater. Chem. A, 9 [8] 4945-51 (2021).

42. B. Cao, G.M. Veith, J.C. Neuefeind, R.R. Adzic, P.G. 
Khalifah, "Mixed close-packed cobalt molybdenum nitrides as non-noble metal electrocatalysts for the hydrogen evolution reaction." J. Am. Chem. Soc., 135 [51] 19186-92 (2013).

43. C.G. Morales-Guio, M.T. Mayer, A. Yella, S.D. Tilley, M. Grätzel, X. Hu, “An optically transparent iron nickel oxide catalyst for solar water splitting." J. Am. Chem. Soc., 137 [31] 9927-36 (2015).

44. C.C. McCrory, S. Jung, J.C. Peters, T.F. Jaramillo, "Benchmarking heterogeneous electrocatalysts for the oxygen evolution reaction." J. Am. Chem. Soc., 135 [45] 16977-87 (2013).

45. X. Jia, Y. Zhao, G. Chen, L. Shang, R. Shi, X. Kang, G.I.N. Waterhouse, L.-Z. Wu, C.-H. Tung, T. Zhang, " $\mathrm{Ni}_{3} \mathrm{FeN}$ Nanoparticles Derived from Ultrathin NiFeLayered Double Hydroxide Nanosheets: An Efficient Overall Water Splitting Electrocatalyst." Adv. Energy Mater, 6 [10] 1502585 (2016).

46. Y. Wang, C. Xie, D. Liu, X. Huang, J. Huo, S. Wang, "Nanoparticle-Stacked Porous Nickel-Iron Nitride Nanosheet: A Highly Efficient Bifunctional Electrocatalyst for Overall Water Splitting." ACS Appl. Mater. Interfaces, 8 [29] 18652-7 (2016).

47. B. Zhang, C. Xiao, S. Xie, J. Liang, X. Chen, Y. Tang, "Iron-Nickel Nitride Nanostructures in Situ Grown on Surface-Redox-Etching Nickel Foam: Efficient and Ultrasustainable Electrocatalysts for Overall Water Splitting." Chem. Mater., 28 [19] 6934-41 (2016).

48. Q. Chen, R. Wang, M. Yu, Y. Zeng, F. Lu, X. Kuang, X. Lu, "Bifunctional Iron-Nickel Nitride Nanoparticles as Flexible and Robust Electrode for Overall Water Splitting." Electrochim. Acta, 247 [1]

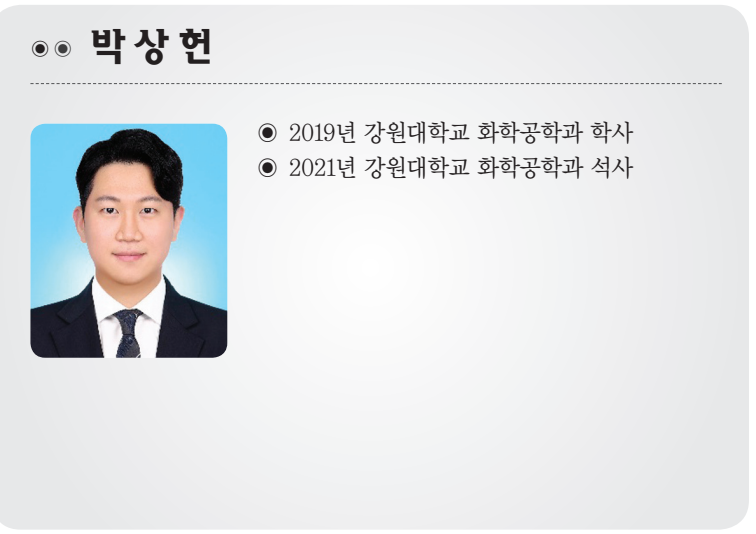

666-73 (2017).

49. Y. Wang, B. Zhang, W. Pan, H. Ma, J. Zhang, "3D Porous Nickel-Cobalt Nitrides Supported on Nickel Foam as Efficient Electrocatalysts for Overall Water Splitting." ChemSusChem, 10 [21] 4170-7 (2017).

50. Y. Qian, I.A. Khan, D. Zhao, "Electrocatalysts derived from metal-organic frameworks for oxygen reduction and evolution reactions in aqueous media." Small, 13 [37] 1701143 (2017).

51. M. Kuang, Q. Wang, P. Han, G. Zheng, "Cu, Coembedded $\mathrm{N}$-enriched mesoporous carbon for efficient oxygen reduction and hydrogen evolution reactions." Adv. Energy Mater., 7 [17] 1700193 (2017).

52. X.F. Lu, L.F. Gu, J.W. Wang, J.X. Wu, P.Q. Liao, G.R. $\mathrm{Li}$, "Bimetal-organic framework derived $\mathrm{CoFe}_{2} \mathrm{O}_{4} /$ $\mathrm{C}$ porous hybrid nanorod arrays as high-performance electrocatalysts for oxygen evolution reaction." $A d v$. Mater. 29 [3] 1604437(2017).

53. D.Y. Heo, S.Y. Kim, "Review of Perovskite Solar Cells Using Metal-Organic Framework Materials(in Korean)." Ceramist, 23 [4] 358-88 (2020).

54. C. Yu, Y. Wang, J. Cui, D. Yu, X. Zhang, X. Shu, J. Zhang, Y. Zhang, R. Vajtai, P.M. Ajayan, "MOF-74 derived porous hybrid metal oxide hollow nanowires for high-performance electrochemical energy storage." J. Mater. Chem. A, 6 [18] 8396-404 (2018).

55. X. Feng, H. Wang, X. Bo, L. Guo, "Bimetal-Organic Framework-Derived Porous Rodlike Cobalt/Nickel Nitride for All-pH Value Electrochemical Hydrogen Evolution." ACS Appl. Mater. Interfaces, 11 [8] 801824 (2019).

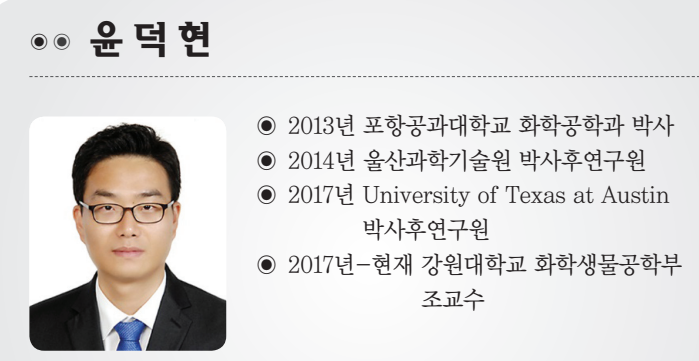

